( 2022 , The Authors. Published by Elsevier Inc. and Fass Inc. on behalf of the American Dairy Science Association ${ }^{\circledR}$. This is an open access article under the CC BY license (http://creativecommons.org/licenses/by/4.0/).

\title{
Effect of gonadotropin-releasing hormone administered at the time of artificial insemination for cows detected in estrus by conventional estrus detection or an automated activity-monitoring system
}

\author{
A. M. Hubner, ${ }^{1}$ I. F. Canisso, ${ }^{1,2 *}$ P. M. Peixoto, ${ }^{1}$ A. J. Conley, ${ }^{3}$ and F. S. Lima ${ }^{3 *}$ \\ ${ }^{1}$ Department of Veterinary Clinical Medicine, University of Illinois, Urbana 61802 \\ 2Department of Comparative Biosciences, University of Illinois, Urbana 61802 \\ ${ }^{3}$ Department of Population Health and Reproduction, School of Veterinary Medicine, University of California, Davis 95616
}

\begin{abstract}
The objectives of this study were to determine the effects of GnRH at the time of artificial insemination (AI) on ovulation, progesterone $7 \mathrm{~d}$ post-AI, and pregnancy in cows detected in estrus using traditional methods (tail chalk removal and mount acceptance visualization) or an automated activity-monitoring (AAM) system. We hypothesized that administration of $\mathrm{GnRH}$ at the time of AI would increase ovulation rate, plasma progesterone post-AI, and pregnancy per $\mathrm{AI}(\mathrm{P} / \mathrm{AI})$ in cows detected in estrus. In experiment 1, Holstein cows $(\mathrm{n}=398)$ were blocked by parity and randomly assigned to receive an injection of $\mathrm{GnRH}$ at the time of estrus detection/AI ( $\mathrm{GnRH}, \mathrm{n}=197)$ or to remain untreated (control, $\mathrm{n}=201$ ) on 4 farms. The $\mathrm{GnRH}$ was administered as $100 \mu \mathrm{g}$ of gonadorelin acetate. Ovarian structures and plasma progesterone were assessed in a subset of cows (GnRH, $\mathrm{n}=52$; control, $\mathrm{n}=55$ ) in experiment 1 at the time of AI and $7 \mathrm{~d}$ later. In experiment 2, a group of 409 cows in an AAM farm were enrolled as described for experiment $1(\mathrm{GnRH}, \mathrm{n}=$ 207; control, $\mathrm{n}=202$ ). Data were categorized for parity (primiparous vs. multiparous), season (cool vs. warm), number of services (first vs. $>$ first), DIM ( $>150$ DIM vs. $\leq 150$ DIM), and for AAM cows in experiment 2 for activity level (high: 90-100 index vs. low: 35-89 index). Pregnancy diagnosis was performed between 32 and 45 d post-AI (P1) and 60 to 115 d post-AI (P2). In experiment 1 , there was no difference in plasma progesterone at day of estrus detection (control $=0.09 \mathrm{ng} / \mathrm{mL}$ vs. $\mathrm{GnRH}=0.16 \mathrm{ng} / \mathrm{mL}), 7 \mathrm{~d}$ later $($ control $=2.03 \mathrm{ng} / \mathrm{mL}$ vs. $\mathrm{GnRH}=2.18 \mathrm{ng} / \mathrm{mL})$, and ovulation rate $(\mathrm{GnRH}=$ $83.2 \%$ vs. control $=77.9 \%$ ) between treatments. There were no effects of $\mathrm{GnRH}$ in experiment 1 for $\mathrm{P} / \mathrm{AI}$ at
\end{abstract}

Received July 14, 2021.

Accepted September 7, 2021.

*Corresponding authors: falima@ucdavis.edu and canisso@illinois .edu
$\mathrm{P} 1($ control $=43.3 \%$ vs. $\mathrm{GnRH}=38.6 \%), \mathrm{P} 2($ control $=38.4 \%$ vs. $\mathrm{GnRH}=34.5 \%$ ), and for pregnancy loss (control $=9.8 \%$ vs. $\mathrm{GnRH}=8.2 \%)$. In experiment 2 , there were no effects of GnRH for P/AI at P1 (control $=39.6 \%$ vs. $\mathrm{GnRH}=40.1 \%), \mathrm{P} 2$ (control $=35.0 \%$ vs. $\mathrm{GnRH}=37.4 \%$ ), and for pregnancy loss (control $=$ $9.5 \%$ vs. $\mathrm{GnRH}=6.2 \%$ ). There was a tendency for a parity effect on $\mathrm{P} / \mathrm{AI}$ for $\mathrm{P} 1$, but not $\mathrm{P} 2$ or for pregnancy loss. High-activity cows had greater P/AI in P1 (low activity $=27.9 \%$ vs. high activity $=44.1 \%$ ), P2 (low activity $=21.8 \%$ vs. high activity $=41.2 \%$ ), and lower pregnancy loss (low activity $=20.7 \%$ vs. high activity $=5.1 \%$ ), but there were no interactions between treatment and activity level. The current study did not support the use of GnRH at estrus detection to improve ovulatory response, progesterone 1 wk post-AI, and $\mathrm{P} /$ AI. More research is needed to investigate the relationship between GnRH at the time of AI and activity level in herds using AAM systems.

Key words: estrus detection, activity monitor, GnRH, estradiol

\section{INTRODUCTION}

For lactating dairy cows in the United States, the use of AI after detected estrus (AIDE) remains a common practice reported to be used in over $60 \%$ of AI on dairy farms (NAHMS, 2014). Many farms continue to use estrus detection after administration of $\mathrm{PGF}_{2 \alpha}$, followed by enrolling cows that did not receive insemination into a synchronization program for the first services and as a means to rapidly re-inseminate cows after a failed insemination (NAHMS, 2014). The use of $\mathrm{PGF}_{2 \alpha}$ for estrus induction leads to multiple cows in estrus 2 to 5 d later (Lauderdale, 1972), helping concentrate farm personnel efforts to detect estrus activity. Indeed, estrus detection and activity in lactating dairy cows have been critically evaluated, and evidence indicates that the identification of the modern dairy cow in estrus is challenging. Previous exploration of interventions 
to improve pregnancy per AI ( $\mathbf{P} / \mathbf{A I})$ in AIDE in the 1980s and 1990s suggests that an injection of $\mathrm{GnRH}$ at or around $\mathrm{AI}$ increases $\mathrm{P} / \mathrm{AI}$ in lactating dairy cows (Roussel et al., 1988; Stevenson et al., 1988; Chenault, 1990). Indeed, a large meta-analysis concluded that GnRH at the time of AIDE increased P/AI by $12.5 \%$ (Morgan and Lean, 1993), but the results varied according to the number of services, the dose of GnRH, and if cows were classified as repeat-breeders or not. Additionally, the greatest increase in $\mathrm{P} / \mathrm{AI}$ were associated with the smallest studies. More recent studies in farms using automated activity monitors (AAM) had inconsistent results. A study conducted in Wisconsin (Valenza et al., 2012) reported no benefits of GnRH in cows with relatively low $\mathrm{P} / \mathrm{AI}$, whereas benefits of $\mathrm{GnRH}$ in cows with low estrus activity $(\mathrm{GnRH}=$ $40.0 \%$ vs. no $\mathrm{GnRH}=30.8 \%$ ) were found in a study conducted in British Columbia, Canada (Burnett et al., 2019). It remains unclear if this simple practice is effective for our modern lactating dairy cattle under today's management practices or whether this practice is effective relative to the type of estrus detection method [AAM or no-AAM (tail chalk removal and mounting acceptance visualization)].

It has been demonstrated that lactating dairy cows do not always ovulate when detected in estrus (Sartori et al., 2004; López-Gatius et al., 2005; Valenza et al., 2012). Additionally, lactating dairy cows may benefit from increased levels of progesterone post-AI (Wiltbank et al., 2011; Monteiro et al., 2014). An injection of $\mathrm{GnRH}$ at the time of AIDE may reduce delayed ovulation (Bloch et al., 2006), increase the proportion of cows ovulating, and increase progesterone concentration post-AI (Mee et al., 1993). The objectives of this study were to determine the effects of $\mathrm{GnRH}$ at the time of AI on ovulation, progesterone $7 \mathrm{~d}$ post-AI, and pregnancy outcomes of cows detected in estrus using no-AAM methods. A second objective was to compare the effect of GnRH at the time of insemination on $\mathrm{P} /$ AI in AAM cows. The hypotheses for the current study were that ovulation rates and progesterone $7 \mathrm{~d}$ post-AI would increase in cows treated with GnRH in no-AAM cows and lead to increased P/AI. We also hypothesized that cows detected in estrus by a commercially available AAM (Heatime, SCR Engineers) system would have improvement in $\mathrm{P} / \mathrm{AI}$ for cows treated with $\mathrm{GnRH}$.

\section{MATERIALS AND METHODS}

\section{Study Population, Housing, and Diets}

Experiment 1 was conducted from October 2019 to October 2020 on 4 commercial dairy farms in Illinois.
The size of the farms ranged from 100 to 3,300 lactating Holstein cows (farm A: 410; farm B: 100; farm C: 3,300; farm D: 140), and the rolling herd average milk production varied from 11,800 to $14,091 \mathrm{~kg} /$ cow per year (farm A: $12,575 \mathrm{~kg}$; farm B: $11,800 \mathrm{~kg}$; farm C: 14,091 kg; farm D: 12,730 kg). Holstein lactating cows on all 4 farms were housed in freestall barns with sand bedding. Farms A and B milked twice daily, whereas farms C and D milked thrice daily. Cows on each of the 4 farms were detected in estrus by conventional means (tail chalk removal and mounting acceptance visualization).

Experiment 2 was conducted from October 2019 to October 2020 on a single Illinois dairy farm (farm E). The farm size was 310 lactating cows and had a rolling herd average milk production of $10,100 \mathrm{~kg} /$ cow per year. Cows were housed in a freestall barn bedded with dry solid manure. The farm milked twice daily. The farm used a neck-mounted AAM system (Heatime SCR Engineers) fitted to the upper left side of the cranial portion of the cow's neck. Activity data were recorded every $2 \mathrm{~h}$ using a wireless receiver box, transmitting the data to a receiving unit connected to the farm manager's computer. The raw activity data from each cow was used to determine the index value closely associated with the standard deviation of the peak activity (calculated using the raw peak of activity value and baseline values of the previous $14 \mathrm{~d}$ ). Index values varied from 0 to 100, and the threshold for an episode of high activity was established as 35 .

For experiments 1 and 2, all farms fed a TMR formulated to meet or exceed the nutritional requirements for the respective level of milk production (NRC, 2001), which was fed once daily on each farm. Cows on each farm had free access to water. All animal procedures followed the recommendations of the Guide for the Care and Use of Agricultural Animals in Research and Teaching (FASS, 2010).

\section{Study Design, Treatments, and Reproductive Management}

In experiments 1 and 2, cows detected in estrus were eligible to be enrolled in the study unless the cow had not reached the end of the voluntary waiting period, she was enrolled in a synchronization program, or was deemed a "do not breed." Eligible cows detected in estrus were blocked by parity and randomly assigned to either receive an injection of $\mathrm{GnRH}$ at the time of $\mathrm{AI}$ $(\mathrm{GnRH})$ or remain untreated (control) in experiments 1 and 2 .

In experiment 1,398 cows were enrolled $(\mathrm{GnRH}, \mathrm{n}=$ 197; control, $\mathrm{n}=201$; farm $\mathrm{A}: \mathrm{n}=101$; farm $\mathrm{B}: \mathrm{n}=71$; 
farm C: $\mathrm{n}=171$; farm $\mathrm{D}: \mathrm{n}=55$ ). Treatment of $\mathrm{GnRH}$ (100 $\mu \mathrm{g}$ of gonadorelin acetate, $1 \mathrm{~mL}$ of Gonabreed, Parnell) was administered on all farms using singledose syringes with 18-gauge 1.5-inch needles in the semimembranosus or semitendinosus muscles of the cows. Treatment on 4 of the 5 farms was administered by farm personnel, and treatment was administered by the study personnel on 1 farm (farm C). The reproductive programs used in the farms in experiment 1 were a combination of AI after estrus detection and timed AI performed after Presynch-Ovsynch (PO) or DoubleOvsynch (DO; farm A: PO; farm B: PO; farm C: DO; farm D: DO) for first service and different variations of Ovsynch for resynchronization. Insemination on each farm was conducted by the herd owner or by a farm employee. Commercial semen from multiple sires purchased by each farm were used in the study.

In experiment 2, a group of 409 cows were enrolled (GnRH, $\mathrm{n}=207$; control, $\mathrm{n}=202$ ). Treatment of $\mathrm{GnRH}$ (100 $\mathrm{g}$ of gonadorelin acetate, $1 \mathrm{~mL}$ of Gonabreed) was administered using single-dose syringes with 18-gauge 1.5-inch needles in the semimembranosus or semitendinosus muscles of the cows. The reproductive programs used in experiment 2 were mostly AI after estrus detection and timed AI performed after PO for first service or Ovsynch for resynchronization. Insemination was conducted by the herd owner. Commercial semen purchased from multiple sires were used in the study.

\section{Ultrasonography Examination of Ovarian Responses}

In experiment 1, a subset of cows from farm $\mathrm{C}(\mathrm{GnRH}$, $\mathrm{n}=52$ and control, $\mathrm{n}=55$ ) had ovaries mapped during the study to characterize the response to $\mathrm{GnRH}$ injection. Transrectal ultrasonography examinations were performed at the time of $\mathrm{GnRH}$ injection and $7 \mathrm{~d}$ later. Blood was collected at the time of both ultrasonography examinations ( $\mathrm{GnRH}, \mathrm{n}=52$; control, $\mathrm{n}=55$ ). Cows with a corpus luteum $(\mathbf{C L})$ on either ovary at the time of estrus detection were not eligible to be enrolled in the subset used for the study. For this subset of cows, ultrasonography and GnRH injection were performed by study personnel. All ultrasonographic examinations were carried out using an Easi-Scan coupled with a 7.5-MHz linear probe (Easi-Scan, BCF Technologies). The largest diameter of each follicle $>12 \mathrm{~mm}$ and CL $>12 \mathrm{~mm}$ were estimated using gridlines on the ultrasound image. Fluid-filled cavities in CL were measured in the same fashion. The volume of a CL was calculated by subtracting the cavity volume from the total CL volume. The volume was calculated using $4 / 3 \times \pi \times$ $0.5 \mathrm{D}^{3}$, where $\mathrm{D}=$ diameter. Ovulation was characterized by the appearance of a new functional CL ( $>1 \mathrm{ng} /$
$\mathrm{mL}$ of plasma progesterone concentration) in the place of a previous ovulatory follicle $7 \mathrm{~d}$ after AI.

\section{Blood Collection and Hormonal Assays}

In experiment 1, blood was collected from the coccygeal vessels using a vacutainer with an 18-gauge 1-inch needle into a 10-mL EDTA tube. Blood samples were immediately placed on ice. Blood samples were centrifuged at $2,000 \times g$ for $15 \mathrm{~min}$ at $4^{\circ} \mathrm{C}$ within $3 \mathrm{~h}$ of collection. Plasma was pipetted from the sample and stored in $2-\mathrm{mL}$ microcentrifuge tubes at $-20^{\circ} \mathrm{C}$ until hormone assays were completed. On 2 farms, pregnancy diagnosis was performed by blood-serum testing for pregnancy-associated glycoproteins at a commercial laboratory.

Hormonal steroid assays were performed at the Clinical Endocrinology laboratory at the University of California, Davis, under the supervision of Alan Conley. Plasma progesterone was measured using a competitive enzyme immunoassay as described and validated recently by Gomez et al. (2018). Plasma concentrations of estradiol were measured using modifications to a commercially available estradiol RIA kit (Beckman Coulter Ultra-Sensitive RIA DSL-4800) recently validated for use in cattle (Swanepoel et al., 2020). Intra-assay coefficients of variation were $14.2 \%$ for progesterone and $7.5 \%$ for estradiol. Interassay coefficients of variation were $6.6 \%$ for progesterone and $4.2 \%$ for estradiol.

\section{Pregnancy Diagnosis}

In experiment 1, 2 farms used a commercial serum testing for pregnancy diagnosis (BioPRYN, Affiliate Laboratory). For the other 2 farms, one farm relied on their herd veterinarian for pregnancy diagnosis, and final farm pregnancy exams were performed by study personnel for the other farm. In experiment 2, pregnancy diagnosis was performed by the herd veterinarian. Regardless of pregnancy diagnosis method, initial pregnancy diagnosis was performed between d 32 and 45 post-AI (P1; farm A: 32-45 d, farm B: $32-38 \mathrm{~d}$, farm C: $35-41$, farm D: 32-45 d, farm E: 32-45 d) and the second pregnancy diagnosis was performed between d 60 and 115 post-AI (P2; farm A: 60-73 d, farm B: 60-73 d, farm C: 67-73 d, farm D: 60-73 d, farm E: 102-115 d) depending on each farm's regular herd visit schedule.

\section{Statistical Analysis}

Power analyses were performed using G Power 3 (Universität Düsseldorf). The sample size was calcu- 
lated to detect a difference in $\mathrm{P} / \mathrm{AI}$. For the subset of cows, the sample size was calculated to detect a difference in progesterone concentrations $7 \mathrm{~d}$ after AI. The expected difference in $\mathrm{P} / \mathrm{AI}$ was $12.5 \%$ based on a large meta-analysis evaluating differences in $\mathrm{P} / \mathrm{AI}$ for cows receiving $\mathrm{GnRH}$ at or around the time of $\mathrm{AI}$ (Morgan and Lean, 1993). The sample size was calculated considering the $\mathrm{P} / \mathrm{AI}$ increasing from 35 to $47.5 \%$ with an $\alpha$ error probability of $5 \%$ and a power of $80 \%$ using a one-tailed test. This power analysis resulted in a total sample size for 392 cows (196 cows per treatment group) for experiments 1 and 2 . The expected difference in plasma progesterone was $1.5 \mathrm{ng} / \mathrm{mL}$, based on the minimum difference in plasma progesterone for cows administered GnRH that could be expected to improve P/AI (Monteiro et al., 2014). Considering a change in plasma progesterone on d 7 post-AI from $2.0 \mathrm{ng} / \mathrm{mL}$ in control to $3.5 \mathrm{ng} / \mathrm{mL}$ for cows receiving $\mathrm{GnRH}$, with an $\alpha$ error probability of $5 \%$ and a power of $90 \%$ using a 2 -tailed test, the total sample size for the subset of cows was calculated to be 88 total cows. Additional cows were added to account for possible attrition of cows before the data were finalized.

In experiments 1 and 2 , categorical data $(\mathrm{P} / \mathrm{AI}$ for $\mathrm{P} 1$ and $\mathrm{P} 2$, pregnancy loss, and ovulation rate) were analyzed by logistic regression using the GLIMMIX procedure of SAS version 9.4 (SAS/STAT, SAS Institute Inc.), fitting a binary distribution response. Continuous data (diameter of largest follicle, volume of largest follicle, diameter of largest CL, total luteal volume of the CL, plasma estradiol, and plasma progesterone) were analyzed using the MIXED procedure of SAS. Data were tested for normality of residuals using the UNIVARIATE procedure of SAS. Independent variables considered for each experiment parity (primiparous vs. multiparous), season (warm = MayOctober vs. cool $=$ November-April), DIM at the time of AI (DIM $<150$ vs. DIM $\geq 150$ ), number of services (1 vs. $\geq 2$ ), and 2-way interactions for treatment and all variables and between methods of estrus detection and the other variables. In experiment 1 , farm was also included in the models as a fixed effect. In experiment 2 , activity level (high $=90-100$ index vs. low $=35-89$ ) was also included in the models as a fixed effect. Logistic regression and receiver operating characteristic (ROC) curves were used to generate a threshold to predict pregnancy at P2 based on serum concentration of estradiol. Statistical significance was determined if $P$ $<0.05$, and statistical tendency was determined if 0.05 $\leq P<0.10$.

\section{RESULTS}

\section{Descriptive Statistics}

As expected, there were no differences in lactation number and percent of primiparous and multiparous cows between treatments for experiment 1 (no-AAM) and 2 (AAM; Table 1). In experiment 1, for no-AAM cows, the GnRH group had a higher $(P=0.02)$ number of services and lower percentage $(P=0.05)$ of cows receiving AI after the first service than cows in the control group (Table 1). The number of services and percent of cows receiving AI for the first service was not different between treatments in experiment 2. The milk production average per day in the 3 tests before AI and the percent of cows producing more than $45.4 \mathrm{~kg} / \mathrm{d}$ were not different between treatments in experiments 1 and 2 (Table 1 ).

\section{Ovarian Responses and Progesterone and Estradiol Concentrations}

In experiment 1 , a subset $(\mathrm{n}=108)$ of no-AAM cows were assessed for ovarian structures and plasma progesterone and estradiol concentrations at the time of $\mathrm{AI}$ and $7 \mathrm{~d}$ later. Before $\mathrm{GnRH}$ administration, there was a tendency $(P=0.08)$ for cows in the GnRH group to have a larger follicle diameter than cows in the control group at enrollment. Still, no differences were present

Table 1. Description of animals treated with GnRH or remaining untreated (control) in experiment 1 (farms using conventional methods, no $\mathrm{AAM}=$ visualization of mounting acceptance or tail chalk removal) and experiment 2 (farms using automated activity monitors; AAM)

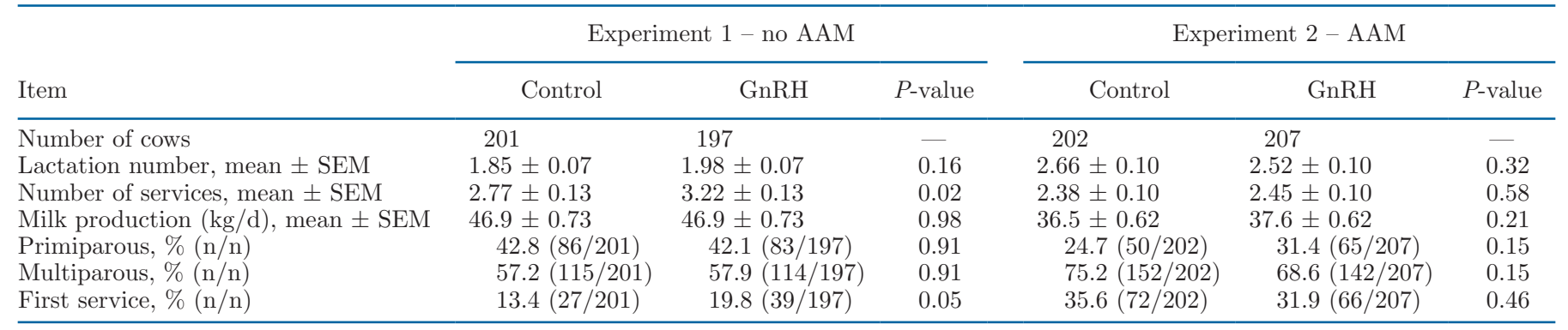


Table 2. Ovarian dynamics and plasma progesterone concentration at the time of AI at detected estrus (AIDE)/enrollment (d 0) and $7 \mathrm{~d}$ after AIDE, and plasma estradiol concentration at AIDE for cows receiving GnRH or remaining untreated at AIDE in experiment 1 (farms using conventional methods, no automated activity monitoring $=$ visualization of mounting acceptance or tail chalk removal)

\begin{tabular}{|c|c|c|c|}
\hline Item & $\begin{array}{c}\text { Control } \\
(\text { mean } \pm \text { SEM })\end{array}$ & $\begin{array}{c}\text { GnRH } \\
(\text { mean } \pm \text { SEM })\end{array}$ & $P$-value \\
\hline Number of cows & 56 & 52 & - \\
\hline Ovulatory follicle diameter, d 0 (mm) & $18.8 \pm 0.46$ & $20.0 \pm 0.48$ & 0.08 \\
\hline Progesterone concentration, d 0 (ng/mL) & $0.16 \pm 0.04$ & $0.09 \pm 0.04$ & 0.21 \\
\hline Estradiol concentration, d 0 (pg/mL) & $5.52 \pm 0.62$ & $5.23 \pm 0.55$ & 0.71 \\
\hline Ovulation rate, \% (n/n) & $92.8 \pm 3.7(52 / 58)$ & $90.4 \pm 3.9(47 / 52)$ & 0.64 \\
\hline Progesterone concentration, d 7 post AI $(\mathrm{ng} / \mathrm{mL})$ & $2.18 \pm 0.15$ & $2.03 \pm 0.15$ & 0.51 \\
\hline
\end{tabular}

for follicle volume $(P=0.12)$ and ovulation rate $(P=$ $0.64)$ between control and GnRH (Table 2). Additionally, there were no differences between GnRH and control for luteal diameter $(P=0.60)$ and luteal volume $(P$ $=0.66)$ at $\mathrm{d} 7$ post-AI (Table 2).

There was no difference $(P=0.51)$ in plasma progesterone concentration between $\mathrm{GnRH}$ and control at the time of enrollment, nor was there a difference in plasma progesterone $7 \mathrm{~d}$ after enrollment $(P=0.51)$ between GnRH and control cows (Table 2). There was also no difference $(P=0.71)$ in plasma estradiol between GnRH and control at the time of enrollment (Table 2).

\section{Pregnancy Outcomes}

In experiment 1 , for no-AAM cows, there were no differences in $\mathrm{P} / \mathrm{AI}$ at $\mathrm{P} 1(P=0.45)$, $\mathrm{P} 2(P=0.54)$, and for pregnancy loss $(P=0.63)$ between control and $\mathrm{GnRH}$ (Figure 1A). No statistical significance $(P$ $>0.10$ ) was found for P1, P2, and pregnancy loss for the covariates farm, parity, season, DIM, number of services (Figure 2), and the 2-way interactions between covariates and treatment.

In experiment 2, for AAM cows, there were no differences in $\mathrm{P} / \mathrm{AI}$ at $\mathrm{P} 1(P=0.73), \mathrm{P} 2(P=0.40)$, and for
Pregnancy outcomes for No-AAM farms according to treatment A

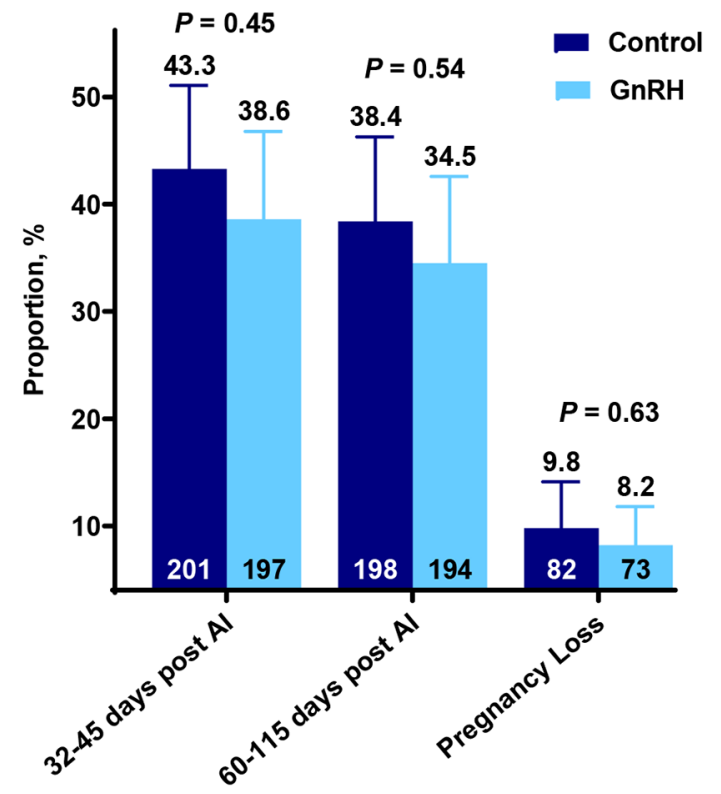

\section{Pregnancy outcomes for AAM farm according to treatment}

B

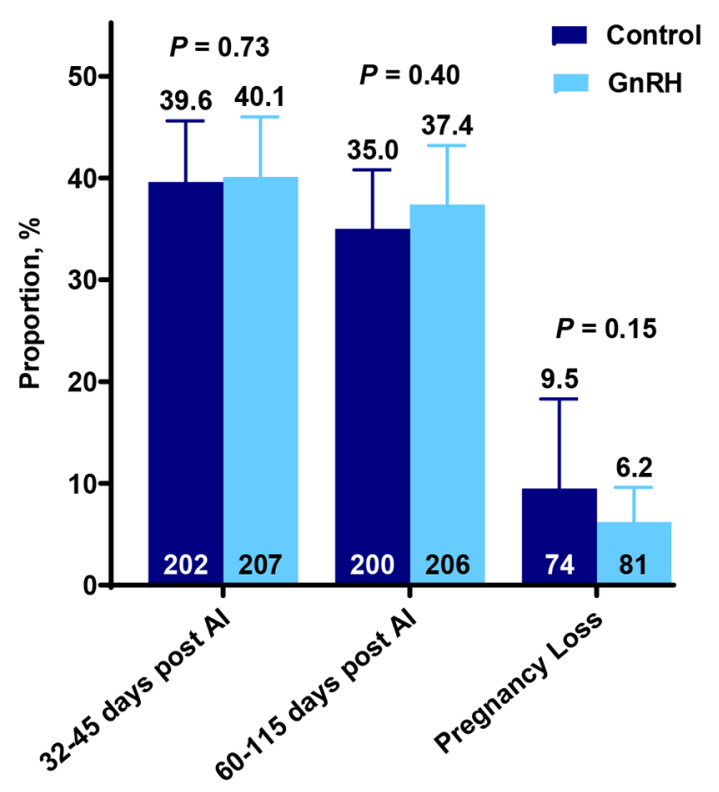

Figure 1. Proportion of pregnant cows at pregnancy diagnosis 1 (P1; 32-45 d post-AI), 2 (P2; 60-115 d post-AI), and pregnancy loss cows according to treatments (control = AI after estrus detection untreated or GnRH $=100 \mu \mathrm{g}$ of gonadorelin acetate and $1 \mathrm{~mL}$ of Gonabreed; Parnell) in experiment 1 (A) with farms using conventional methods (no-AAM = visualization of mounting acceptance or tail chalk removal), or experiment 2 (B) on a farm using automated activity monitors (AAM). Error bars represent the SEM. 
pregnancy loss $(P=0.15)$ between control and $\mathrm{GnRH}$ (Figure 1B). There was a tendency for an effect of parity (primiparous vs. multiparous) at P1 (primiparous: $47.8 \pm 6.3$; multiparous: $36.7 \pm 3.9 ; P=0.05)$, and an effect at P2 (primiparous: $44.7 \pm 6.3$; multiparous: $32.9 \pm 3.8 ; P=0.04)$, but there was no difference for pregnancy loss (primiparous: $5.8 \pm 4.7$; multiparous: $8.7 \pm 5.2 ; P=0.42)$ between primiparous and multiparous cows. Cows with high activity level had greater $\mathrm{P} / \mathrm{AI}$ in $\mathrm{P} 1(P=0.005), \mathrm{P} 2(P<0.001)$, and lower pregnancy loss $(P=0.009$; Figure 3$)$ than herd mates with low activity level. Interactions between treatment and activity level were not present in $\mathrm{P} 1(P=0.48), \mathrm{P} 2$ $(P=0.85)$, and for pregnancy loss $(P=0.43$; Figure $3)$. In experiment 2 , no statistical significance $(P>$ 0.10 ) was present for P1, P2, and pregnancy loss for the covariates season, DIM, and the 2-way interactions between covariates and treatment, whereas there was a tendency $(P=0.10)$ for greater $\mathrm{P} / \mathrm{AI}$ at $\mathrm{P} 1$ for number of services $\geq 2$ compared with $\mathrm{P} / \mathrm{AI}$ for first service (Figure 2).
In experiment 1 at enrollment before treatment, there was also an effect of serum estradiol concentration at d 0 on $\mathrm{P} / \mathrm{AI}$; however, there was no interaction between estradiol quartile and treatment for P1 $(P=0.20), \mathrm{P} 2(P=0.25)$, and pregnancy loss $(P$ $=0.75)$. Logistic regression and ROC curve analysis were conducted using plasma estradiol as a criterion to predict pregnancy at $\mathrm{P} 2$. When plasma estradiol was used to predict proportion pregnant using ROC curve analysis, a cut-point of $\leq 6.91 \mathrm{pg} / \mathrm{mL}$ was found to have the optimized sensitivity and specificity (sensitivity $=0.94$, specificity $=0.42)$, with low estradiol being predictive of higher $\mathrm{P} / \mathrm{AI}$ (Figure 4 ). When cows were categorized based on the cut-point of $\leq 6.91$, cows below that cut-point had a significantly greater $\mathrm{P} / \mathrm{AI}$ (low estradiol $=45.7 \%$, high estradiol $=6.7 \% ; P=$ $0.001)$. When cows were divided into quartiles $(\mathbf{Q} ; 1-4)$ based on estradiol levels, cows in the highest estradiol quartile (Q4) had significantly lower P/AI $(P<0.01)$ than cows in quartiles 1 and $2(\mathrm{Q} 1=65.4 \%, \mathrm{Q} 2=$ $50.0 \%, \mathrm{Q} 3=42.3 \%, \mathrm{Q} 4=18.5 \%)$.

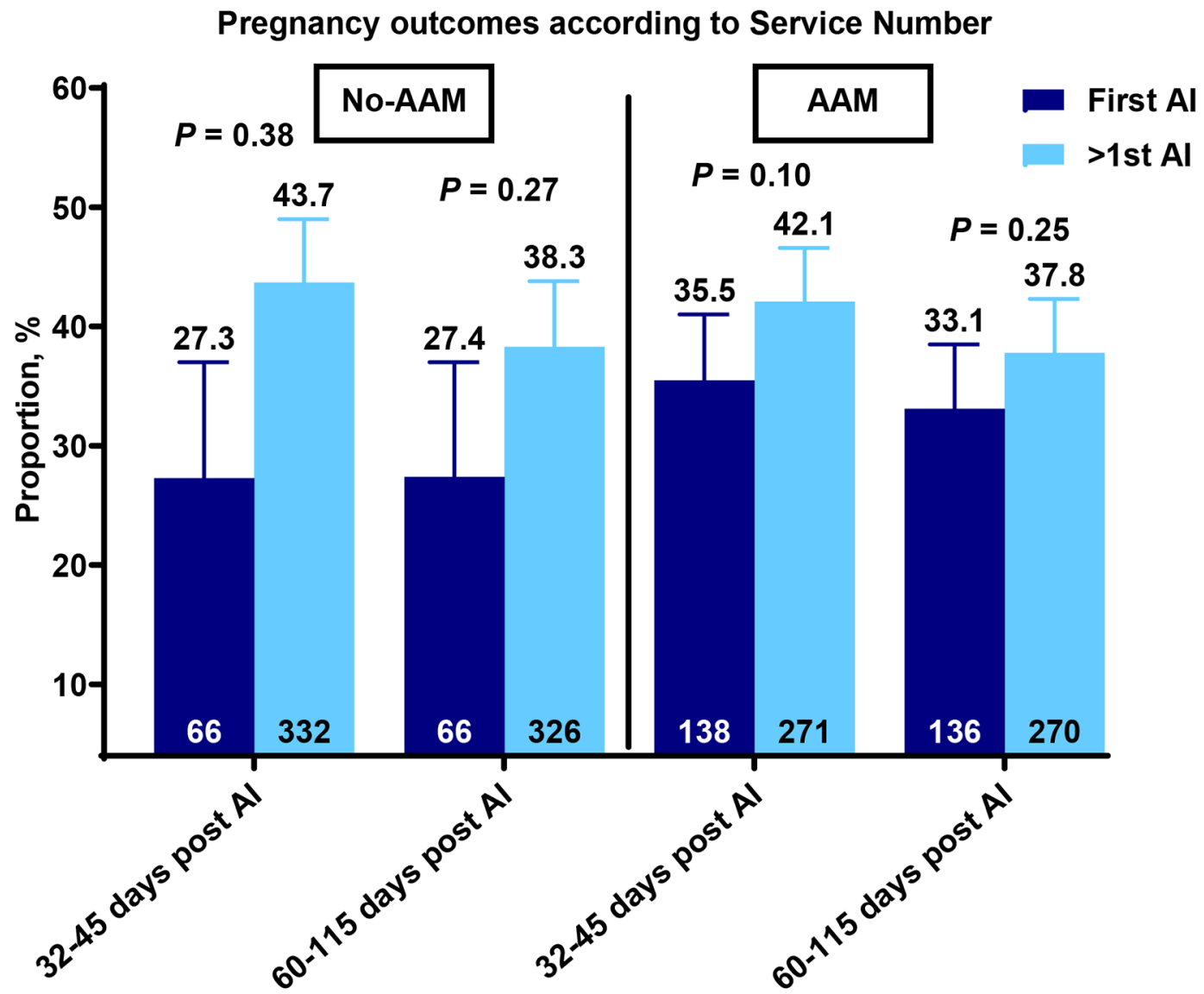

Figure 2. Conventional estrus detection (no-AAM) and automated activity monitors (AAM): proportion of pregnant cows at pregnancy diagnosis 1 (P1; 32-45 d post AI) and 2 (P2; 60-115 d post AI) according to number of service (first vs. > first AI) for in experiment 1 (NoAAM) or experiment 2 (AAM). Error bars represent the SEM. 
Pregnancy outcomes according to treatment and estrus activity level

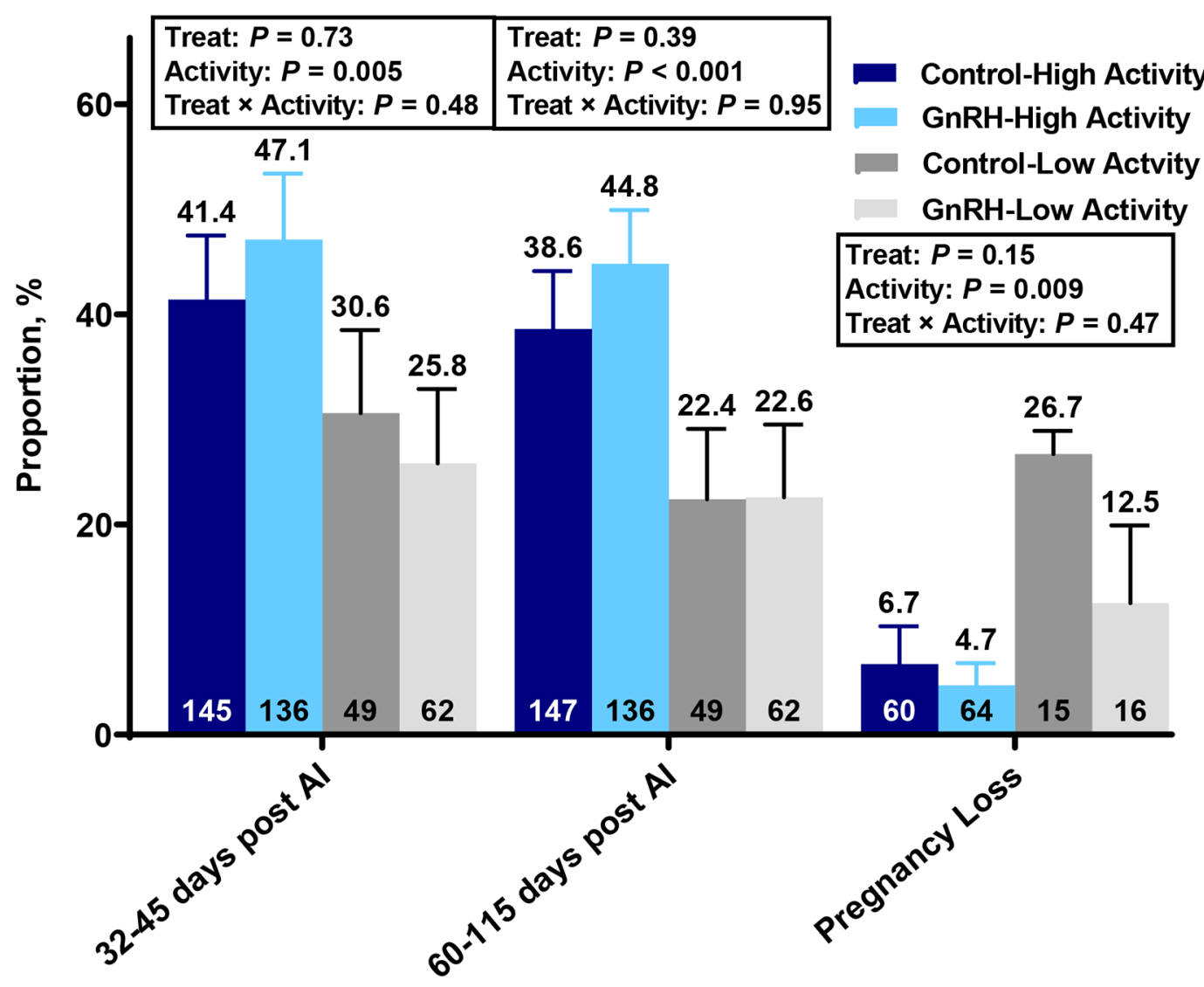

Figure 3. Proportion of pregnant cows at pregnancy diagnosis 1 (P1; 32-45 d post AI), 2 (P2; 60-115 d post AI), and pregnancy loss in cows detected in estrus using automated activity-monitoring system according to treatments (control = AI after estrus detection untreated or GnRH; $100 \mu \mathrm{g}$ of gonadorelin acetate and $1 \mathrm{~mL}$ of Gonabreed; Parnell) and activity level (high $=90-100$ index and low $=35-89$ index) in experiment 2 (farm using automated activity monitors; AAM). Error bars represent the SEM.

\section{DISCUSSION}

The use of AI after estrus detection in dairy farms remains a significant component of reproductive programs in North America (NAHMS, 2014; DenisRobichaud et al., 2018). The rationale and motives for the current study were based on 3 premises. First, the recent evidence of $\mathrm{GnRH}$ benefits in cows detected in estrus using AAM (Burnett et al., 2019) was limited to low-activity cows. Second, the benefits of GnRH at the time of estrus found by a meta-analysis (Morgan and Lean, 1993) were linked to benefits to repeat-breeders and dose of $\mathrm{GnRH} \geq 250 \mu \mathrm{g}, 2$ nonpervasive conditions in the current dairy industry in North America. Third, the range of cows detected in estrus that fail to ovulate, 6.5 to $44 \%$ (Sartori et al., 2004; López-Gatius et al., $2005)$, or have delayed $(>35 \mathrm{~h}$ after estrus $=10 \%)$ ovulation (Bloch et al., 2006) is higher in no-AAM than in recent AAM studies that range between 1.3 and $5.0 \%$
(Valenza et al., 2012; Schilkowsky et al., 2021). Thus, the experiment for no-AAM was designed to test the hypothesis that an injection of GnRH at the time of AIDE would increase ovulation rate and progesterone concentration $7 \mathrm{~d}$ after $\mathrm{AI}$, and affect $\mathrm{P} / \mathrm{AI}$ in cows detected in estrus using no-AAM methods such as tail chalk removal or mount acceptance visualization. The second experiment for AAM was designed to test the hypothesis that injection of $\mathrm{GnRH}$ at the time of $\mathrm{AI}$ would increase $\mathrm{P} / \mathrm{AI}$ in cows detected in estrus using $\mathrm{AAM}$ and once more re-evaluate the nuanced response in low and high-activity cows.

The current results for no-AAM did not support our hypothesis that $\mathrm{GnRH}$ administered at the time of estrus detection would improve ovulation rate and progesterone $7 \mathrm{~d}$ after AI, 2 physiological responses expected to affect pregnancy outcomes (Mee et al., 1993; Valenza et al., 2012). Increasing ovulation rate would have clear implications for conception rate, as cows 


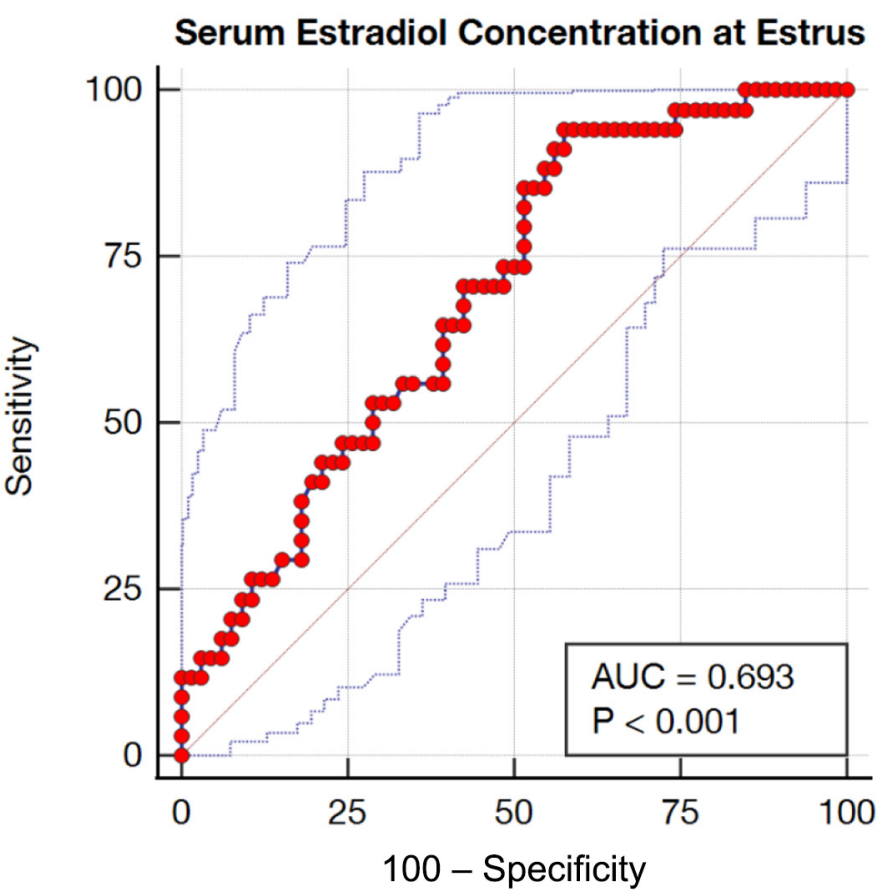

Figure 4. Receive operator characteristics curve to predict pregnancy at d 60 to 115 using estradiol concentration at day of estrus detection and AI. The test generated a threshold of $\leq 6.91 \mathrm{pg} / \mathrm{mL}$ of serum concentration of estradiol in experiment 1 (farms using conventional methods; no-AAM = visualization of mounting acceptance or tail chalk removal). AUC = area under the curve.

that fail to ovulate are unable to become pregnant. Increasing progesterone after AI is expected to increase conceptus growth, thereby increasing interferon-tau and improving signaling for maternal recognition of pregnancy (MRP; Kerbler et al., 1997; Brooks et al., 2014). Because MRP occurs before the time for pregnancy diagnosis in commercial farms, improvement in signaling for MRP would be detected as an increase in $\mathrm{P} / \mathrm{AI}$. Consistent with the physiological responses, pregnancy outcomes failed to be improved by GnRH treatment in either no-AAM or AAM-detected cows, which agrees with Valenza et al. (2012). In this previous study, the authors attributed the lack of difference in $\mathrm{P} / \mathrm{AI}$ to a small percent of cows failing to ovulate $(5 \%)$ at the time of insemination that could benefit from $\mathrm{GnRH}$ treatment. It is noteworthy that even the meta-analysis of 40 trials showing a $12.5 \%$ higher pregnancy risk for cows receiving GnRH failed to find benefit for doses of less than $125 \mu \mathrm{g}$ (Morgan and Lean, 1993), which is aligned with the findings of the current study. Studies indicate that doubling the dose of $\mathrm{GnRH}$ from 100 to $200 \mu \mathrm{g}$ increases LH release (Giordano et al., 2012) and ovulation (Chenault et al., 2014; Ariciniega et al., 2020). Still, benefits reported from that study seemed linked to cows having high progesterone at the time of GnRH treatment, unlikely the case for cows detected in estrus, such as in the current study.

Burnett et al. (2019) demonstrated that for cows detected in estrus using AAM, GnRH at the time of AI improved P/AI for those cows with low activity levels (Burnett et al., 2019). When we analyzed data in the current study for high and low activity, we could not replicate the benefits from the previous study (Burnett et al., 2019). Although not significant, our results had indications of potential benefits of $\mathrm{GnRH}$ in cows detected with high activity with $\mathrm{P} / \mathrm{AI}$ at $\mathrm{P} 1$ and $\mathrm{P} 2$ of 47.1 and $44.8 \%$, respectively, for GnRH versus 41.3 and $38.6 \%$ for control cows. In examining the discrepancy of results of $\mathrm{GnRH}$ administration in estrus detected using AAM (previous work showing benefit to low activity cows), we noticed an increase in P/AI for highactivity cows (Burnett et al., 2019). We acknowledge that the lack of significance of the current study should be interpreted with caution. Still, future studies need to critically evaluate the relationship between estrus activity level detected by AAM and the benefits of GnRH.

Another interesting finding of this study was the substantial increase in P/AI (19.4\%) in high-activity cows when compared with low-activity cows in AAM (low activity $=21.8 \%$ vs. high activity $=41.2 \%$ ). Although high-activity cows have demonstrated higher pregnancy per AI in previous studies, the magnitude of increase in $\mathrm{P} / \mathrm{AI}$ between high- and low-activity cows has been lower, ranging from 10.6 to $13.5 \%$ (Madureira et al., 2015; Burnett et al., 2017). Farms that experience substantial differences in P/AI between low- and highactivity cows may need additional strategies to improve P/AI. The previous study by Burnett et al. (2019) explored this possibility with success, but unfortunately our results did not align with those from that study. Further exploration is needed to assess potential benefits of GnRH on fertility for low-activity cows detected in estrus across a range of dairy farms.

Another curious finding of the current study was a counterintuitive tendency for lower P/AI for cows receiving the first service compared with herd mates receiving $\geq 2$ services. The meta-analysis of 40 trials listed above underscores that the benefit of $\mathrm{GnRH}$ administration at AI was only present for $\geq 2$ services (Morgan and Lean, 1993). Valenza et al. (2012) were unable to replicate the benefits of $\mathrm{GnRH}$ for $\geq 2$ services. Despite the improved $\mathrm{P} / \mathrm{AI}$ for $\geq 2$ services, we failed to find an interaction between service and treatment in the current study. In a general population, pregnancy risk for the first service is higher than $\geq 2$ services (Giordano et al., 2015; Stangaferro et al., 2018), or at least similar 
between the first and second service (Marques et al., 2020). The rationale for these expected results is that the first service included the entire population with a significant number of high-fertility cows that would become pregnant at the first opportunity. In contrast, $\geq 2$ services would have the percentage of high-fertility cows become pregnant in the first service subtracted from its denominator. The lower first service P/AI independent of treatment for the current study was likely an artifact for no-AAM. Two of the farms with higher $\mathrm{P} / \mathrm{AI}$ in the study performed mostly timed AI for their first service. One factor that may affect estrus detection accuracy and activity level is the use of $\mathrm{PGF}_{2 \alpha}$ administration that leads to multiple cows in estrus on the same day. The relationship of AIDE after $\mathrm{PGF}_{2 \alpha}$ treatment, estrus activity level, and benefits of $\mathrm{GnRH}$ is a facet of this research field that deserves further investigation.

We analyzed estradiol to have a snapshot of its concentration at the time of insemination and potential to determine a proxy for ongoing high activity in no-AAM cows. Within the subset of cows with estradiol analyzed at the time of enrollment, there was a significant association between estradiol levels and P/AI with high concentrations of estradiol associated with lower P/AI compared with lower estradiol concentrations. Previous studies reported a spectrum of relationships between estradiol concentration, estrus duration, and ovulation (Saumande and Humblot, 2005; Bloch et al., 2006). A study revealed a negative correlation between the preovulatory estradiol concentrations and duration of the estrus to LH peak and estradiol to ovulation interval (Saumande and Humblot, 2005). A second study found that cows experiencing delayed ovulation had a lower estradiol concentration at estrus detection (Bloch et al., 2006). It has been discussed that delayed ovulation reduces the odds of successful fertilization. The short fertile half-life of male and female bovine gametes limits the period during which fertilization can take place (Dransfield et al., 1998; Nebel et al., 2000). Indeed, it has been demonstrated that the oocyte fertilization rate declines substantially 8 to $12 \mathrm{~h}$ postovulation, and insemination 25 to $40 \mathrm{~h}$ before ovulation is linked with reduced conception (Hunter, 1994). For the most part, the intervals between the onset of estrus and ovulation in beef and dairy cattle varied from 23 to $33 \mathrm{~h}$ (Mikeska and Williams, 1988; Lemaster et al., 1999; Bloch et al., 2006), with the mean in lactating dairy cows being $27 \mathrm{~h}$ (Walker et al., 1996). The current study results suggest that the group of cows with very high estradiol might be more likely to have a longer interval from estrus detection and AI to ovulation and reduced odds of viable gametes being available for fertilization. Although the results of a snapshot assessment of estradiol concentration at the time of insemination seemed helpful in predicting pregnancy outcomes, we must acknowledge that there was a lack of data determining the onset of estrus in the current study. Thus, caution should be used when interpreting the implications of the current study. The characterization of activity level and serial estradiol concentration around estrus time might offer opportunities to refine the use of GnRH in a specific subset of AAM cows. Estradiol is a steroid hormone present in low plasma concentration with wide variation during estrus in cattle, making its determination and adoption as a tool to refine decisions in the dairy industry challenging (Ginther et al., 2013). However, the characterization of other steroid hormones related to estradiol during estrus might shed light on a more realistic target for a cow-side biomarker to refine estrus prediction in cattle.

\section{CONCLUSIONS}

Administration of GnRH at the time of AIDE did not increase ovulation rate and $\mathrm{P} / \mathrm{AI}$ in experiment 1 for cows detected in estrus using no-AAM methods, nor $\mathrm{P} / \mathrm{AI}$ for cows in experiment 2. Moreover, administration of $\mathrm{GnRH}$ at the time of AI did not affect plasma progesterone levels $7 \mathrm{~d}$ after AI. Additional examination of $\mathrm{GnRH}$ treatment at the time of $\mathrm{AI}$ in multiple farms using AAM based on activity level is warranted. Moreover, an analysis of plasma estradiol concentration that considers the variation of activity level over time might help to identify a subset of cows benefiting from GnRH treatment in AAM farms.

\section{ACKNOWLEDGMENTS}

We thank the herds involved in this study, including Stoneridge Dairy (Mansfield, IL), Ravendale Holsteins (Freeburg, IL), Scidmore Dairy (Chadwick, IL), Dall Dairy (Aviston, IL), and Indian Creek Farms (Fairbury, IL). In addition, we thank Parnell Living Science (Kansas City, MO) for their generous donation of products used in the current study. We also thank the Department of Population Health at the School of Veterinary Medicine at the University of California, Davis, which provided F. S. Lima's start-up funds to cover hormonal assay analysis. The authors have not stated any conflicts of interest.

\section{REFERENCES}

Ariciniega, T. V., I. M. R. Leao, E. A. Galvan, T. O. Cunha, M. S. El Azzi, N. B. Cook, and J. P. N. Martins. 2020. Effect of a high dose of gonadorelin hydrochloride at the first gonadotropin-releasing 
hormone of the breeding-Ovsynch of a fertility program on ovulation rate and pregnancies per AI in first-service lactating Holstein cows. J. Dairy Sci. 103:92.

Bloch, A., Y. Folman, M. Kaim, Z. Roth, R. Braw-Tal, and D. Wolfenson. 2006. Endocrine alterations associated with extended time interval between estrus and ovulation in high-yield dairy cows. J. Dairy Sci. 89:4694-4702. https://doi.org/10.3168/jds.S0022 -0302(06)72520-6.

Brooks, K., G. Burns, and T. E. Spencer. 2014. Conceptus elongation in ruminants: Roles of progesterone, prostaglandin, interferon tau and cortisol. J. Anim. Sci. Biotechnol. 5:53. https://doi.org/10 $.1186 / 2049-1891-5-53$.

Burnett, T. A., A. M. L. Madureira, J. W. Bauer, W. A. Gomes, and R. L. A. Cerri. 2019. Interaction of estrous expression and progesterone on the impact of $\mathrm{GnRH}$ administration at the time of AI on pregnancy and ovulation rates. J. Dairy Sci. 102:275.

Burnett, T. A., A. M. L. Madureira, B. F. Silper, A. C. C. Fernandes, and R. L. A. Cerri. 2017. Integrating an automated activity monitor into an artificial insemination program and the associated risk factors affecting reproductive performance of dairy cows. J. Dairy Sci. 100:5005-5018. https://doi.org/10.3168/jds.2016-12246.

Chenault, J. R. 1990. Effect of fertirelin acetate or buserelin on conception rate at first or second insemination in lactating dairy cows. J. Dairy Sci. 73:633-638. https://doi.org/10.3168/jds.S0022 -0302(90)78714-0.

Chenault, J. R., D. M. Meeuwse, C. LaGrow, J. K. Tena, S. L. WoodFollis, and J. W. Hallberg. 2014. Evaluation of gonadotropin-releasing hormone hydrogen chloride at 3 doses with prostaglandin F2alpha for fixed-time artificial insemination in dairy cows. J. Dairy Sci. 97:2816-2821. https://doi.org/10.3168/jds.2013-7453.

Denis-Robichaud, J., R. L. A. Cerri, A. Jones-Bitton, and S. J. LeBlanc. 2018. Dairy producers' attitudes toward reproductive management and performance on Canadian dairy farms. J. Dairy Sci. 101:850-860. https://doi.org/10.3168/jds.2016-12416.

Dransfield, M. B., R. L. Nebel, R. E. Pearson, and L. D. Warnick. 1998. Timing of insemination for dairy cows identified in estrus by a radiotelemetric estrus detection system. J. Dairy Sci. 81:18741882. https://doi.org/10.3168/jds.S0022-0302(98)75758-3.

FASS. 2010. Guide for the care and use of agricultural animals in research and teaching. FASS.

Ginther, O. J., F. L. Pinaffi, F. A. Khan, L. F. Duarte, and M. A. Beg. 2013. Follicular-phase concentrations of progesterone, estradiol$17 \beta, \mathrm{LH}, \mathrm{FSH}$, and a $\mathrm{PGF}_{2 \alpha}$ metabolite and daily clustering of prolactin pulses, based on hourly blood sampling and hourly detection of ovulation in heifers. Theriogenology 79:918-928. https:// doi.org/10.1016/j.theriogenology.2012.12.015.

Giordano, J. O., P. M. Fricke, J. N. Guenther, G. Lopes Jr., M. M. Herlihy, A. B. Nascimento, and M. C. Wiltbank. 2012. Effect of progesterone on magnitude of the luteinizing hormone surge induced by two different doses of gonadotropin-releasing hormone in lactating dairy cows. J. Dairy Sci. 95:3781-3793. https://doi.org/ 10.3168/jds.2011-5155.

Giordano, J. O., M. L. Stangaferro, R. Wijma, W. C. Chandler, and R. D. Watters. 2015. Reproductive performance of dairy cows managed with a program aimed at increasing insemination of cows in estrus based on increased physical activity and fertility of timed artificial inseminations. J. Dairy Sci. 98:2488-2501. https://doi .org/10.3168/jds.2014-8961.

Gomez, N. A., A. J. Conley, and P. H. Robinson. 2018. Effects of longterm, near-term, and real-time energy balance, and blood progesterone concentrations, on the pregnancy rate of contemporary dairy cows. Anim. Reprod. Sci. 189:136-145. https://doi.org/10 .1016/j.anireprosci.2018.01.001.

Hunter, R. H. 1994. Causes for failure of fertilization in domestic species. Pages 1-22 in Embryonic Mortality in Domestic Species. M. T. Zavy and R. D. Geisert, ed. CRC Press.

Kerbler, T. L., M. M. Buhr, L. T. Jordan, K. E. Leslie, and J. S. Walton. 1997. Relationship between maternal plasma progesterone concentration and interferon-tau synthesis by the conceptus in cattle. Theriogenology 47:703-714. https://doi.org/10.1016/S0093 $-691 \mathrm{X}(97) 00028-9$.
Lauderdale, J. W. 1972. Effects of $\mathrm{PGF}_{2 \alpha}$ on pregnancy and estrous cycle of cattle. J. Anim. Sci. 35:247.

Lemaster, J. W., J. V. Yelich, J. R. Kempfer, and F. N. Schrick. 1999. Ovulation and estrus characteristics in crossbred Brahman heifers treated with an intravaginal progesterone-releasing insert in combination with prostaglandin $\mathrm{F}_{2 \alpha}$ and estradiol benzoate. J. Anim. Sci. 77:1860-1868. https://doi.org/10.2527/1999.7771860x.

López-Gatius, F., M. López-Bejar, M. Fenech, and R. H. Hunter. 2005. Ovulation failure and double ovulation in dairy cattle: Risk factors and effects. Theriogenology 63:1298-1307. https://doi.org/10 $.1016 / j$.theriogenology.2004.06.010.

Madureira, A. M., B. F. Silper, T. A. Burnett, L. Polsky, L. H. Cruppe, D. M. Veira, J. L. Vasconcelos, and R. L. Cerri. 2015. Factors affecting expression of estrus measured by activity monitors and conception risk of lactating dairy cows. J. Dairy Sci. 98:7003-7014. https://doi.org/10.3168/jds.2015-9672.

Marques, O., A. Veronese, V. R. Merenda, R. S. Bisinotto, and R. C. Chebel. 2020. Effect of estrous detection strategy on pregnancy outcomes of lactating Holstein cows receiving artificial insemination and embryo transfer. J. Dairy Sci. 103:6635-6646. https://doi .org/10.3168/jds.2019-17892.

Mee, M. O., J. S. Stevenson, B. M. Alexander, and R. G. Sasser. 1993. Administration of $\mathrm{GnRH}$ at estrus influences pregnancy rates, serum concentrations of LH, FSH, estradiol-173, pregnancy-specific protein $\mathrm{B}$, and progesterone, proportion of luteal cell types, and in vitro production of progesterone in dairy cows. J. Anim. Sci. 71:185-198. https://doi.org/10.2527/1993.711185x.

Mikeska, J. C., and G. L. Williams. 1988. Timing of preovulatory endocrine events, estrus and ovulation in Brahman x Hereford females synchronized with norgestomet and estradiol valerate. J. Anim. Sci. 66:939-946. https://doi.org/10.2527/jas1988.664939x.

Monteiro, P. L. Jr., E. S. Ribeiro, R. P. Maciel, A. L. Dias, E. Sole Jr., F. S. Lima, R. S. Bisinotto, W. W. Thatcher, R. Sartori, and J. E. Santos. 2014. Effects of supplemental progesterone after artificial insemination on expression of interferon-stimulated genes and fertility in dairy cows. J. Dairy Sci. 97:4907-4921. https://doi.org/10 $.3168 /$ jds.2013-7802.

Morgan, W. F., and I. J. Lean. 1993. Gonadotrophin-releasing hormone treatment in cattle: A meta-analysis of the effects on conception at the time of insemination. Aust. Vet. J. 70:205-209. https:/ /doi.org/10.1111/j.1751-0813.1993.tb03304.x.

NAHMS. 2014. NAHMS Dairy, Health and Management Practices on U.S. Dairy Operations, 2014. https://www.aphis.usda.gov/animal _health/nahms/dairy/downloads/dairy14/Dairy14_dr_PartIII .pdf.

Nebel, R. L., M. G. Dransfield, S. M. Jobst, and J. H. Bame. 2000. Automated electronic systems for the detection of oestrus and timing of AI in cattle. Anim. Reprod. Sci. 60-61:713-723. https://doi .org/10.1016/S0378-4320(00)00090-7.

NRC. 2001. Nutrient Requirements of Dairy Cattle, 7th rev. ed. Natl. Acad. Press.

Roussel, J. D., J. F. Beatty, and K. Koonce. 1988. Gonadotropin releasing hormone therapy in functional infertility of dairy cattle. Theriogenology 30:1115-1119. https://doi.org/10.1016/0093 $-691 X(88) 90286-5$.

Sartori, R., J. M. Haughian, R. D. Shaver, G. J. M. Rosa, and M. C. Wiltbank. 2004. Comparison of ovarian function and circulating steroids in estrous cycles of Holstein heifers and lactating cows. J. Dairy Sci. 87:905-920. https://doi.org/10.3168/jds.S0022 -0302(04)73235-X.

Saumande, J., and P. Humblot. 2005. The variability in the interval between estrus and ovulation in cattle and its determinants. Anim. Reprod. Sci. 85:171-182. https://doi.org/10.1016/j.anireprosci .2003.09.009.

Schilkowsky, E. M., G. E. Granados, E. M. Sitko, M. Masello, M. M. Perez, and J. O. Giordano. 2021. Evaluation and characterization of estrus alerts and behavioral parameters generated by an earattached accelerometer-based system for automated detection of estrus. J. Dairy Sci. 104:6222-6237. https://doi.org/10.3168/jds .2020-19667. 
Stangaferro, M. L., R. Wijma, M. Masello, M. J. Thomas, and J. O. Giordano. 2018. Extending the duration of the voluntary waiting period from 60 to 88 days in cows that received timed artificial insemination after the Double-Ovsynch protocol affected the reproductive performance, herd exit dynamics, and lactation performance of dairy cows. J. Dairy Sci. 101:717-735. https://doi.org/10 $.3168 /$ jds.2017-13046.

Stevenson, J. S., K. D. Frantz, and E. P. Call. 1988. Conception rates in repeat-breeders and dairy cattle with unobserved estrus after prostaglandin $\mathrm{F}(2)$ alpha and gonadotropin-releasing hormone. Theriogenology 29:451-460. https://doi.org/10.1016/0093 $-691 \mathrm{X}(88) 90247-6$.

Swanepoel, N., P. H. Robinson, and A. J. Conley. 2020. Impacts of substitution of canola meal with soybean meal, with and without ruminally protected methionine, on production, reproduction and health of early lactation multiparous Holstein cows through 160 days in milk. Anim. Feed Sci. Technol. 264(Suppl. 1):114494.
Valenza, A., J. O. Giordano, G. Lopes Jr., L. Vincenti, M. C. Amundson, and P. M. Fricke. 2012. Assessment of an accelerometer system for detection of estrus and treatment with gonadotropin-releasing hormone at the time of insemination in lactating dairy cows. J. Dairy Sci. 95:7115-7127. https://doi.org/10.3168/jds.2012-5639.

Walker, W. L., R. L. Nebel, and M. L. McGilliard. 1996. Time of ovulation relative to mounting activity in dairy cattle. J. Dairy Sci. 79:1555-1561. https://doi.org/10.3168/jds.S0022-0302(96)76517 -7 .

Wiltbank, M. C., A. H. Souza, P. D. Carvalho, R. W. Bender, and A. B. Nascimento. 2011. Improving fertility to timed artificial insemination by manipulation of circulating progesterone concentrations in lactating dairy cattle. Reprod. Fertil. Dev. 24:238-243. https:// doi.org/10.1071/RD11913. 